\title{
Corrigendum
}

\section{Corrigendum to "Effect of Magnetic Field Coupled Deep Cryogenic Treatment on Wear Resistance of AISI 4140 Steel”}

\author{
Liang Tang $\mathbb{D}^{D}$, Xianguo Yan $\mathbb{D}$, Yijiang Jiang, Fan Li, and Haidong Zhang \\ School of Mechanical Engineering, Taiyuan University of Science and Technology, Taiyuan 030024, China \\ Correspondence should be addressed to Xianguo Yan; yan_xg2008@126.com \\ Received 27 April 2021; Accepted 27 April 2021; Published 17 May 2021 \\ Copyright (C) 2021 Liang Tang et al. This is an open access article distributed under the Creative Commons Attribution License, \\ which permits unrestricted use, distribution, and reproduction in any medium, provided the original work is properly cited.
}

In the article titled "Effect of Magnetic Field Coupled Deep Cryogenic Treatment on Wear Resistance of AISI 4140 Steel" [1], the fund number for "the Natural Science Foundation of China (NSFC)" was given incorrectly in the Acknowledgments section. The corrected section appears as follows:

\section{Acknowledgments}

This work was supported by the Natural Science Foundation of China (NSFC) (Grant no. 51675363).

\section{References}

[1] L. Tang, X. Yan, Y. Jiang, F. Li, and H. Zhang, "Effect of magnetic field coupled deep cryogenic treatment on wear resistance of AISI 4140 steel," Advances in Materials Science and Engineering, vol. 2020, Article ID 2589283, 8 pages, 2020. 